Research Article

\title{
Compaction and Breakage Characteristics of Crushed Stone Used as the Backfill Material of Urban Pavement Subsidence
}

\author{
Zhongbing Cai $\mathbb{D}^{1,2}$ Dan Zhang ${ }^{1}{ }^{1},{ }^{1}$ Lang Shi $\left(\mathbb{D},{ }^{1}\right.$ Zhong Chen ${ }^{(D)},{ }^{1}$ Biao Chen ${ }^{(D)}{ }^{1}$ \\ and Suyang Sun ${ }^{1}$ \\ ${ }^{1}$ College of Civil Engineering, Yancheng Institute of Technology, Yancheng, Jiangsu 224051, China \\ ${ }^{2}$ School of Science, Nanjing University of Science \& Technology, Nanjing 210094, China \\ Correspondence should be addressed to Zhongbing Cai; c_zhongbing@ycit.edu.cn
}

Received 7 October 2020; Revised 6 November 2020; Accepted 16 December 2020; Published 24 December 2020

Academic Editor: Hualei Zhang

Copyright ( $\odot 2020$ Zhongbing Cai et al. This is an open access article distributed under the Creative Commons Attribution License, which permits unrestricted use, distribution, and reproduction in any medium, provided the original work is properly cited.

\begin{abstract}
The subsidence of urban pavement is becoming frequent accidents, and backfill is the primary means of remedy. Crushed stone is a commonly used aggregate for backfill material in engineering, and its compaction behavior under load needs to be well understood. In this work, a series of compaction tests were carried out on the same batch of crushed stone samples with the same gradation. The content changes of particles with different sizes were analyzed, the particle breakage characteristics during the compaction process were discussed, and the difference in particle breakage caused by loading speed and loading mode was examined. It shows the following: (1) For all samples, the content of particles that were crushed during compaction was always less than $40 \%$. The particles with the strongest breakage varied with sample gradation. (2) The particle breakage could be divided into four categories: complete fragmentation, complete rupture, local fragmentation, and surface grinding. They affected the particle size distribution after compaction to varying degrees. (3) The particle breakage could be expressed as a cubical parabola of loading speed, whose coefficients are related to the sample gradation. (4) Stepwise loading rendered stronger particle breakage than direct loading, and the increase of particle breakage due to loading mode was more evident for continuous grading samples than discontinuous grading samples. This study will provide an experimental basis and reference for the selection and use of backfill aggregate in urban subsidence areas.
\end{abstract}

\section{Introduction}

During the rapid urban expansion in China, pavement subsidence in urban areas is occurring frequently $[1,2]$. For example, in recent years, several accidents took place in the city of Nantong in the Jiangsu province (Figure 1), with the most recent one on June 29,2020. Subsidence can result from underground drainage pipe leakage $[2,3]$, disturbance from underground construction [4], inadequate backfill [5], soil erosion $[6,7]$, and other situations that alter the stratum and water flow of the underground soil.

Backfill is an indispensable means to remedy subsidence. The materials for backfill often consist of crushed stone particles of different sizes, of which the particle size and gradation are the most important factors that affect the compaction and deformation of backfill materials. Xu et al. [8] examined the compaction of soil-rock mixtures by considering variables as the content of $>5 \mathrm{~mm}$ particles, the maximum filler particle size, and the filler gradation and recommended that the content of coarse material should reach $60 \%-80 \%$, the maximum particle size should be $30 \%$ of the loose paving thickness, and the gradation should be continuous even though no obvious correlation was found between the gradation of the filler and the compaction characteristics of the backfill. Zha [9] found experimentally that the gradation (the Talbot power index $n$ ) of continuous gradation filler had a remarkable impact on the compression response, and the best performance of gangue material against compression was accomplished when $n=0.4$. Liu [10] tested samples with different lithologies and initial particle size gradations under different compaction stress. It was found that gradation had no significant impact on the compaction strain of crushed sandstone, and particle breakage was widespread during compaction. Particle 


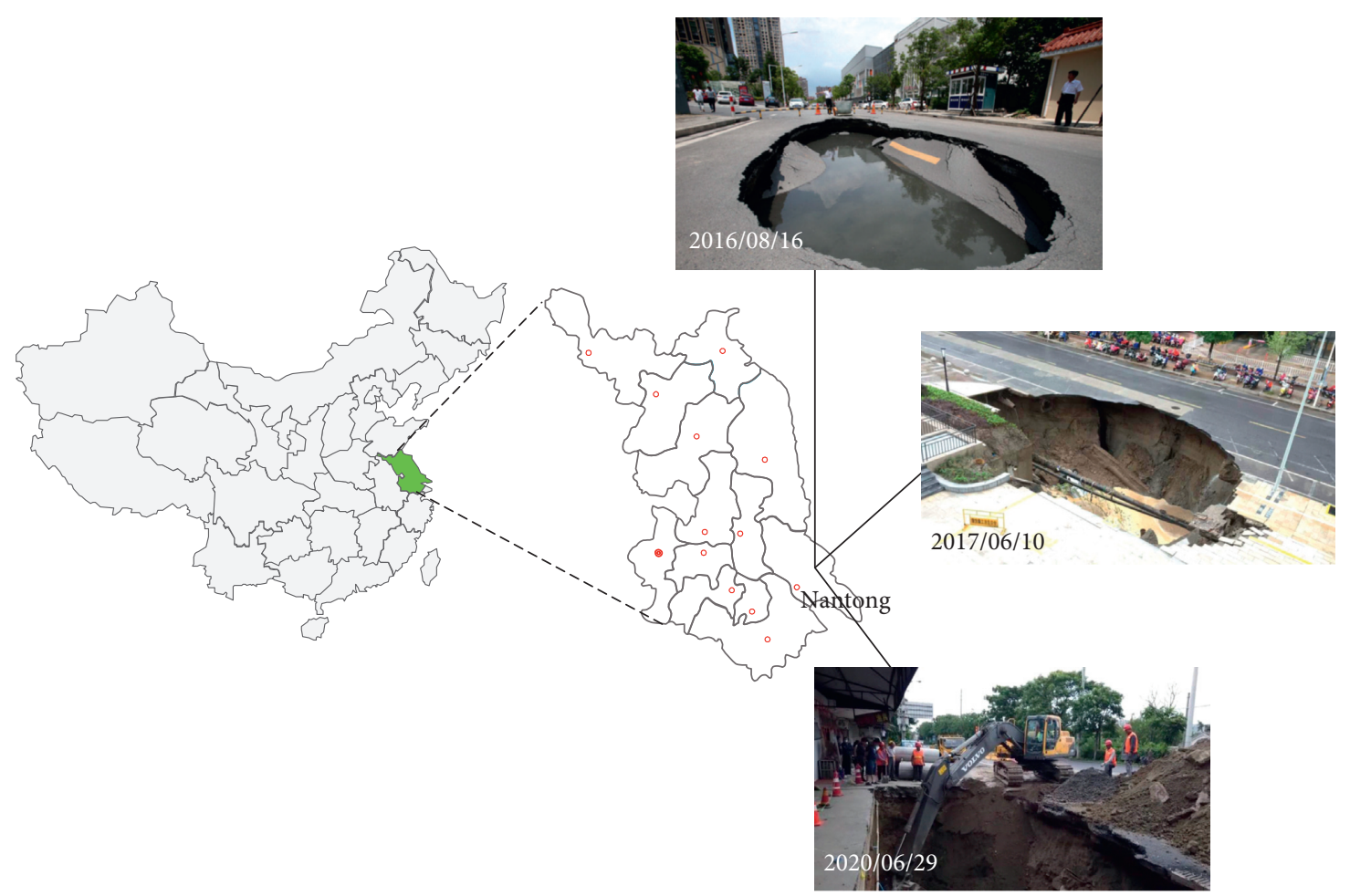

Figure 1: Pavement subsidence in Nantong city in recent years.

breakage changes the gradation and hence the mechanical properties of particulate materials and may even affect structural stability when compaction characteristics change. Coop [11] found that the change in particle gradation caused by particle breakage during the loading process could shrink the sample volume and decrease the peak strength.

Most current studies examined how sample strength and deformation are affected by particle size and gradation and considered primarily compaction and crushing. However, these works mostly focused on the indicators of particle breakage and the changes in the mechanical properties of samples after particle breakage. In fact, factors that affect the load of an urban road also include the frequency and heaviness of traffic. Thus, in studying, the particle breakage of urban roads, influencing factors such as loading speed and loading mode should also be considered; yet to date, their effects on particle breakage have not been reported in detail. In this work, samples with variable gradation were subjected to a series of compaction tests to analyze the changes in the particle content of crushed stone of different sizes. The characteristics of particle breakage during the compaction process were discussed, and the difference in particle breakage caused by loading speed and loading mode was examined. Hence, this work provides an experimental reference for the selection and use of backfill aggregate in urban subsidence areas.

\section{Materials and Methods}

2.1. Sample Preparation. Samples were prepared with crushed mudstone particles of different sizes. According to the ASTM test standard [12], the maximum particle size in the compaction cylinder shall not be greater than $1 / 3$ of the inner diameter of the cylinder. In this work, particles were sieved and sorted into 4 groups based on their size, i.e., $10-15 \mathrm{~mm}, 15-20 \mathrm{~mm}, 20-25 \mathrm{~mm}$, and $25-30 \mathrm{~mm}$ (Figure 2), and Talbot continuous grading [13] was adopted as follows:

$$
p(d)=\left(\frac{d_{i}}{d_{M}}\right)^{n} \times 100 \%,
$$

where $p(d)$ is the percentage of particles whose size is no larger than $d_{i}$, and $d_{M}$ is the maximum particle size.

Table 1 lists the content of particles with different sizes in the tested samples. The sample was prepared either with a $1: 1: 1: 1$ mass ratio of the $10-15 \mathrm{~mm}, 15-20 \mathrm{~mm}$, 20-25 $\mathrm{mm}$, and $25-30 \mathrm{~mm}$ particles or according to the Talbot continuous gradation with the Talbot power index $n$ set to $0.7,0.9,1.1$, and 1.3 . In all samples, a total mass of $2000 \mathrm{~g}$ was charged into the compaction device.

2.2. Equipment. The compaction test system consists of a homemade compaction device, a loading system, and a data acquisition system. The compaction device (Figure 3) is composed of a hollow piston, a cylinder tube, a bottom plate, and other components. The cylinder is $400 \mathrm{~mm}$ in height and has an inner and outer diameter of 160 and $180 \mathrm{~mm}$, respectively. The hollow piston is $250 \mathrm{~mm}$ in height. The loading system is a WDW-100D electronic universal testing machine produced by the Jinan HuaxinYuandaTest Equipment Co., Ltd., which has a maximum testing force of $100 \mathrm{kN}$ with a control accuracy of $1 \%$ for testing force, 


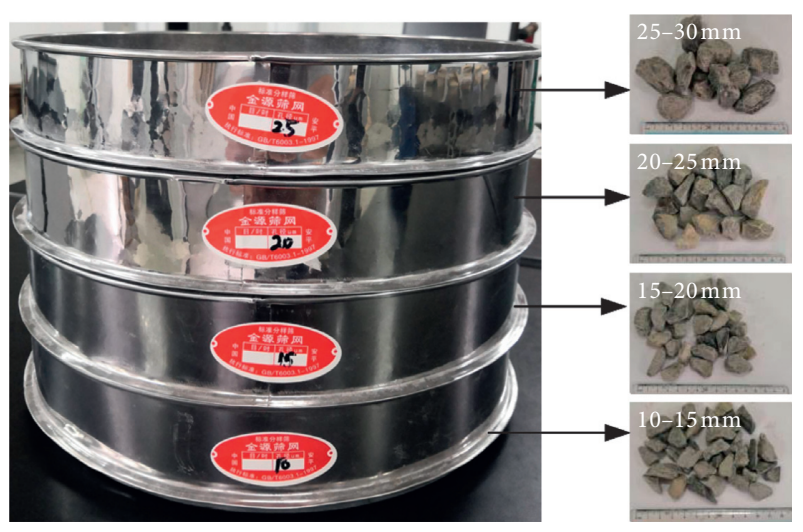

Figure 2: The screen and rock particles.

TABle 1: Particle mass of different samples.

\begin{tabular}{cccccc}
\hline \multirow{2}{*}{ Mass (g) } & \multicolumn{4}{c}{ Particle size (mm) } \\
& & $10-15$ & $15-20$ & $20-25$ & $25-30$ \\
\hline \multirow{4}{*}{ Gradation } & $1: 1: 1: 1$ & 500.0 & 500.0 & 500.0 & 500.0 \\
& $n=0.7$ & 1231.1 & 274.7 & 254.6 & 239.6 \\
& $n=0.9$ & 1071.8 & 316.7 & 308.8 & 302.7 \\
& $n=1.1$ & 933.0 & 347.3 & 356.2 & 363.4 \\
& $n=1.3$ & 812.3 & 368.4 & 397.3 & 422.0 \\
\hline
\end{tabular}

displacement, and speed. During the test, the compaction device was placed in the lower chamber of the WDW-100D testing machine, and the load was applied as the indenter on the testing machine pressed the hollow piston cover.

2.3. Test Scheme. The loading speed was tested at four levels, i.e., $1 \mathrm{~mm} / \mathrm{min}, 2 \mathrm{~mm} / \mathrm{min}, 4 \mathrm{~mm} / \mathrm{min}$, and $6 \mathrm{~mm} / \mathrm{min}$, and the load was applied to $40 \mathrm{~mm}$ either directly or over four steps of $10 \mathrm{~mm}$ each (Table 2). All tests were performed in triplicate, and the average value was taken as the result.

2.4. Procedure. The particles were thoroughly mixed, charged in the compaction cylinder, and then compressed gently. The sample's height $H_{0}$ was then measured before the hollow piston, and the piston cover were installed. To expedite the monitoring of compaction, three scale papers were posted on the outer surface of the hollow piston (Figure 4). The sample was then preliminarily loaded with $0.02 \mathrm{kN}$. The reading of the scale paper was then recorded, and the sample height $H_{1}$ was calculated. The sample was then compacted to the set level at the set speed. Afterward, the sample was discharged and sorted into 7 groups of particles of different sizes, i.e., $0-2 \mathrm{~mm}, 2-5 \mathrm{~mm}, 5-10 \mathrm{~mm}$, $10-15 \mathrm{~mm}, 15-20 \mathrm{~mm}, 20-25 \mathrm{~mm}$, and $25-30 \mathrm{~mm}$. Figure 5 shows the procedure in detail.

\section{Results}

3.1. Changes of Particle Size Distribution after Compaction. Figure 6 shows the particle size distribution of samples before and after direct compaction to $40 \mathrm{~mm}$ at $2 \mathrm{~mm} / \mathrm{min}$.

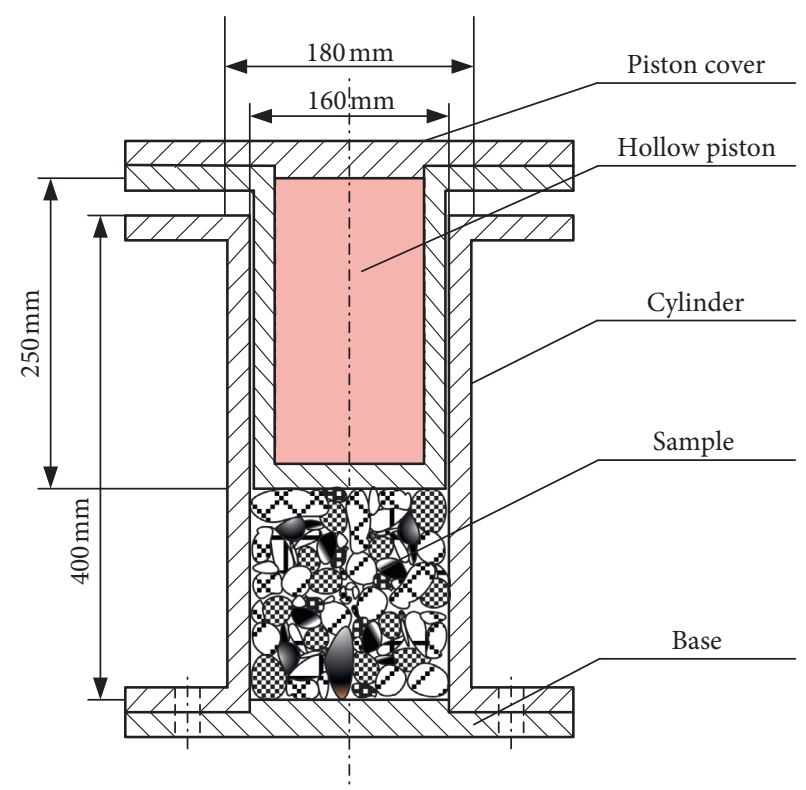

Figure 3: The compaction device.

The mass change of particles of different sizes can be attributed to particle breakage during the compaction process.

In all samples, less than $40 \%$ of the original particles were crushed. Particles with a relatively high level of breakage include the following: $10-15 \mathrm{~mm}$ particles in the sample when $n=0.7$ (39.97\% breakage), $10-15 \mathrm{~mm}$ particles in the sample when $n=1.1$ (37.19\% breakage), $10-15 \mathrm{~mm}$ particles in the $1: 1: 1: 1$ mixed particle size sample $(36.44 \%$ breakage), $20-25 \mathrm{~mm}$ particles in the sample when $n=1.0(34.75 \%$ breakage), and $25-30 \mathrm{~mm}$ particles in the sample when $n=1.3$ (32.44\% breakage). It could be seen that the size of particles with the highest breakage varied with the sample gradation. Particles with a relatively low level of breakage included the following: $25-30 \mathrm{~mm}$ particles in the sample when $n=0.7$ (2.71\% breakage), $10-15 \mathrm{~mm}$ and $15-20 \mathrm{~mm}$ particles in the $1: 1: 1: 1$ mixed particle size sample (about $10 \%$ ), and $15-20 \mathrm{~mm}$ particles in the samples when $n=0.7$ and $n=0.9$ (about 10\%).

The mass changes the largest in the sample when $n=0.7$ and the smallest in the sample when $n=1.3$. That is, particle breakage due to compaction had the least impact on skeletal deformation and structural stability for the sample when $n=1.3$.

3.2. Particle Breakage Characteristics. As stated above, the breakage characteristics of the particles determine how the mass of particles of different size varies after the compaction $[14,15]$. The breakage characteristics are dependent on factors such as the particle arrangement after charging, gradation, loading speed, and loading mode.

After the sample was charged into the compaction device, the particles were arranged in a disorderly manner with relatively poor contact, mainly in the form of point-to-point and point-to-surface contact [16]. Such a sample skeleton composed of large particles was relatively loose, and the internal pores were relatively large. With rising axial stress, 
TABLE 2: Test scheme.

\begin{tabular}{lc}
\hline Loading speed $(\mathrm{mm} / \mathrm{min})$ & Loading mode \\
\hline 1 & \\
2 & Direct loading to $40 \mathrm{~mm}$ \\
4 & \\
6 & Step loading to $40 \mathrm{~mm}$ \\
\hline 2 &
\end{tabular}

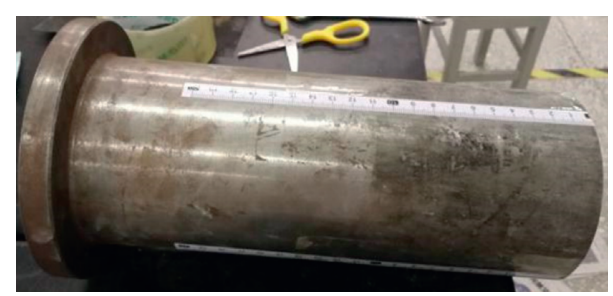

FIgURE 4: The hollow piston posted with scale papers.

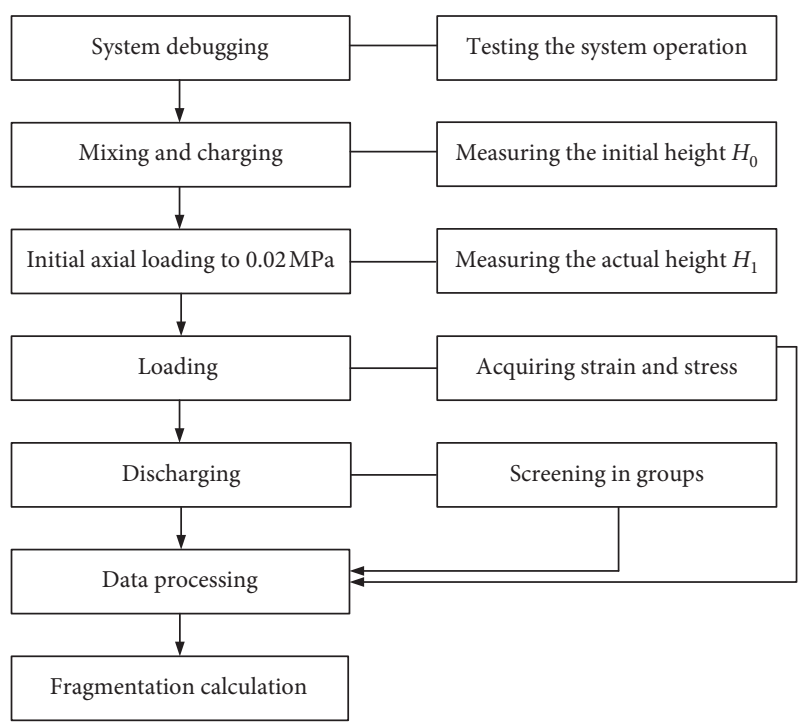

Figure 5: Test procedure.

the pores in the sample became compressed or filled with small particles. Some large particles were crushed to secondary smaller particles, and particle breakage became obvious. The particle size distribution thus changed, causing the relative displacement and rearrangement of particles. The contact between particles gradually changed to surfaceto-surface stable contact and meta-stable contact. Therefore, the particle breakage characteristics and the change of particle size distribution strongly affected the structural stability of the samples.

The breakage characteristics also vary with gradation. Figure 7 shows the crushing of a particular sample, where many particles are broken into secondary and smaller particles. The observed particle breakage could be divided into four categories [17]. The first was complete breakage with multiple breakage sections (A in Figure 7 ), where the

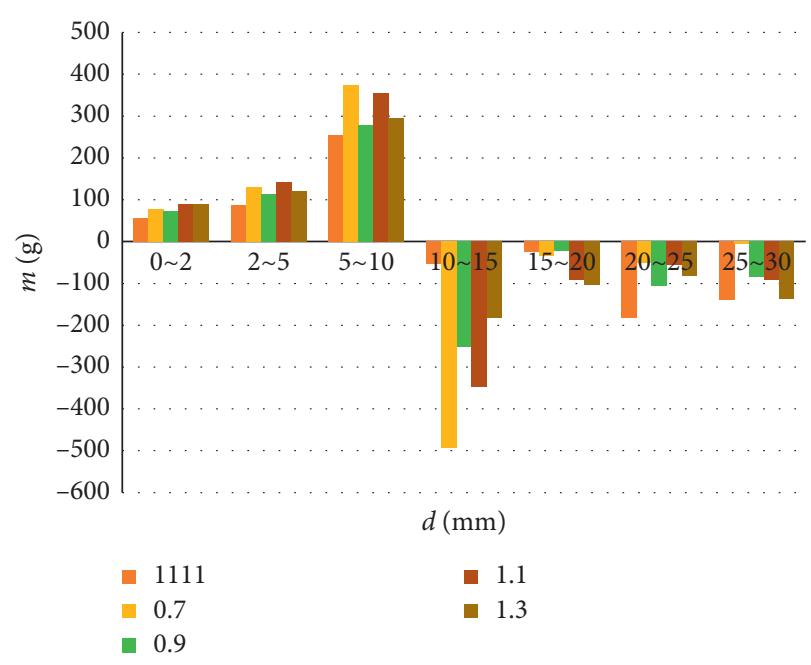

Figure 6: Particle size distribution of samples before and after direct compaction.

original particle was broken into several pieces of smaller particles. The next was also complete breakage but with only one large section (B in Figure 7), generally along the short axis of the particle, and only two secondary particles were produced. The third was local damage due to extrusion that peeled off edges and corners to form one large particle and one or several relatively smaller particles (C in Figure 7 ), for which the section was relatively small and generally located at the sharp corner of particles. The last resulted from surface grinding due to the point-to-surface friction or surface-tosurface contact between particles ( $\mathrm{D}$ in Figure 7), in which case the size and shape of the original particle remained mostly unchanged but many very fine particles were produced at the same time.

The above four types of breakage had varying degrees of impact on the change of particle size distribution. For type A, the size of the resulting broken particles was only about $1 /$ 3 even less than the size of the original particle. For type B, the broken particles were about half of the original particle. For type $\mathrm{C}$, small particles $<5 \mathrm{~mm}$ in size were produced, and the size of the large particle was slightly reduced due to the peeling of edges and corners. For type $\mathrm{D}$, the size of the large particle was almost unchanged and fragments of $<2 \mathrm{~mm}$ in size were produced.

\section{Discussion}

4.1. Quantification of Particle Breakage. Certain indicators are needed to quantify the degree of particle breakage. Liu et al. [18], Wei et al. [19], Einav [20], Hardin [21], Lade et al. [22], Marsal [23], and other scholars have proposed a variety of quantitative indicators of particle breakage. Because of the difficulty in measuring gradation during the experiment, only particle breakage was tested after the compaction was completed, and factors such as the compaction process and the confining pressure were not considered in this work. Therefore, the particle breakage was described by $B_{g}$ as proposed by Marsal [23] as follows: 

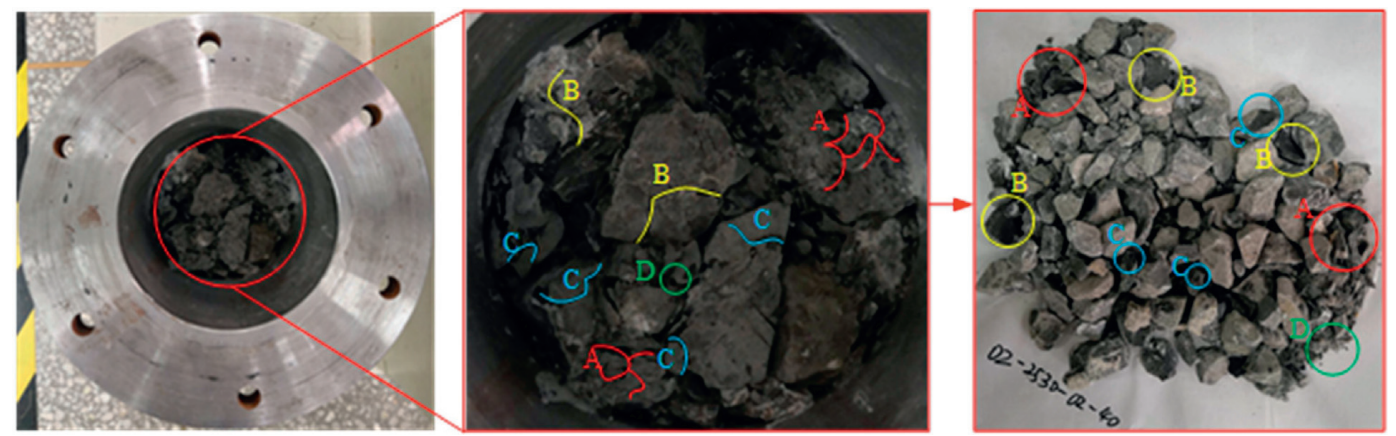

Figure 7: The breakage characteristics after compaction.

TABle 3: The change in particle content under different loading speeds for samples with different gradations.

\begin{tabular}{|c|c|c|c|c|c|c|c|c|c|}
\hline \multirow{2}{*}{\multicolumn{2}{|c|}{$\begin{array}{l}\text { Loading speed } \\
(\mathrm{mm} / \mathrm{min})\end{array}$}} & \multicolumn{7}{|c|}{ Particle size $(\mathrm{mm})$} & \multirow{2}{*}{$B_{g}(\%$} \\
\hline & & $0-2$ & $2-5$ & $5-10$ & $10-15$ & $15-20$ & $20-25$ & $25-30$ & \\
\hline \multirow{4}{*}{$1: 1: 1: 1$} & 1 & 4.18 & 6.24 & 13.23 & -2.29 & -4.78 & -5.08 & -11.50 & 23.64 \\
\hline & 2 & 2.87 & 4.41 & 12.75 & -2.71 & -1.29 & -9.11 & -6.92 & 20.02 \\
\hline & 4 & 3.65 & 5.30 & 12.43 & -1.27 & -0.01 & -8.88 & -11.23 & 21.38 \\
\hline & 6 & 3.71 & 5.36 & 13.86 & -2.87 & -4.12 & -5.86 & -10.12 & 22.93 \\
\hline \multirow{4}{*}{$n=0.7$} & 1 & 4.96 & 7.61 & 19.02 & -21.36 & -2.23 & -5.82 & -2.20 & 31.58 \\
\hline & 2 & 3.90 & 6.58 & 18.67 & -24.63 & -1.69 & -2.48 & -0.33 & 29.14 \\
\hline & 4 & 4.24 & 6.49 & 18.41 & -22.18 & -2.17 & -3.47 & -1.31 & 29.13 \\
\hline & 6 & 3.93 & 6.31 & 18.32 & -24.46 & -1.83 & 0.33 & -2.59 & 28.88 \\
\hline \multirow{4}{*}{$n=0.9$} & 1 & 4.60 & 6.58 & 16.05 & -17.51 & -2.46 & -1.73 & -5.49 & 27.22 \\
\hline & 2 & 3.64 & 5.67 & 13.98 & -12.56 & -1.16 & -5.37 & -4.17 & 23.29 \\
\hline & 4 & 5.10 & 7.72 & 18.43 & -21.96 & -3.06 & -2.36 & -3.86 & 31.24 \\
\hline & 6 & 5.40 & 7.73 & 17.92 & -16.76 & -1.81 & -7.39 & -5.11 & 31.05 \\
\hline \multirow{4}{*}{$n=1.1$} & 1 & 4.70 & 6.65 & 16.04 & -11.48 & -3.66 & -3.26 & -8.91 & 27.38 \\
\hline & 2 & 4.52 & 7.08 & 17.76 & -17.35 & -4.56 & -2.81 & -4.64 & 29.36 \\
\hline & 4 & 4.41 & 6.43 & 16.30 & -11.35 & -4.74 & -4.09 & -6.90 & 27.13 \\
\hline & 6 & 4.77 & 6.77 & 16.17 & -14.15 & -3.50 & -4.02 & -5.98 & 27.70 \\
\hline \multirow{4}{*}{$n=1.3$} & 1 & 4.08 & 6.08 & 14.32 & -7.79 & -1.92 & -7.96 & -6.86 & 24.47 \\
\hline & 2 & 4.55 & 6.00 & 14.75 & -9.09 & -5.23 & -4.13 & -6.85 & 25.30 \\
\hline & 4 & 4.01 & 5.58 & 13.23 & -8.04 & -3.74 & -7.45 & -3.56 & 22.82 \\
\hline & 6 & 4.75 & 6.79 & 15.70 & -8.61 & -2.55 & -9.52 & -6.56 & 27.24 \\
\hline
\end{tabular}

$$
B_{g}=\sum \Delta W_{k},
$$

where $\Delta W_{k}$ is the difference between the content of particles with the different sizes before and after the test and $B_{g}$ is the degree of particle breakage, which is the sum of increments of particles with increasing content and expressed as a percentage.

4.2. Effect of Loading Speed on Particle Breakage. As the loading speed changes, the properties of the material change differently and the degree of particle breakage also varies. Table 3 shows the change in the particle content under different loading speeds for samples with different gradations, along with the corresponding degree of particle breakage. It could be seen that loading speed affects the particle breakage after compaction, and these effects are related to gradation.

Figure 8 shows the relationship between the loading speed and the particle breakage of samples with different gradations.
It can be seen from the figure that, for the samples of $1: 1: 1: 1$ and $n=0.7$, the particle breakage firstly decreased and then increased with escalating loading speed. In contrast, the $n=1.1$ and $n=1.3$ samples show an inverse trend, i.e., the particle breakage firstly increased and then decreased with escalating loading speed. For the sample of $n=0.9$, with the rising loading speed, the particle breakage shows an initial decrease, followed by an increase, and eventually another decrease.

Table 4 shows the relationship between the particle breakage and the loading speed for samples with different gradations. The particle breakage could be expressed as a cubical parabola of loading speed, whose coefficients are related to the sample gradation.

4.3. Influence of Loading Mode on Particle Breakage. The loading mode also affects particle breakage during compaction. Table 5 shows the content change of particles with different sizes and the corresponding particle breakage after the samples were compacted $40 \mathrm{~mm}$ under the two loading modes, i.e., direct loading and stepwise loading. In stepwise 


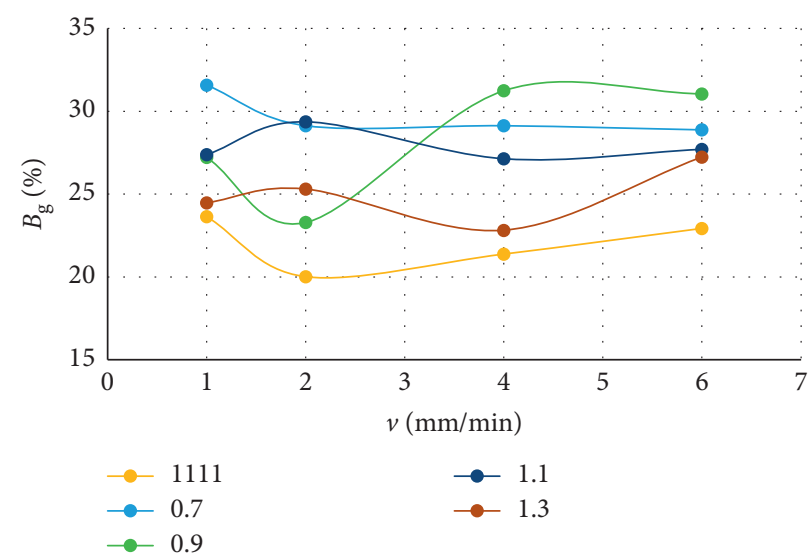

FIGURE 8: The relationship between the loading speed and the particle breakage of samples.

TABLE 4: The expressions of particle breakage.

\begin{tabular}{lcc}
\hline Samples & $B_{g}(\%)$ & $R^{2}$ \\
\hline $1: 1: 1: 1$ & $B_{g}=\left(-0.282 v^{3}+3.4076 v^{2}-11.869 v+32.383\right) \times 100 \%$ & 1.00 \\
$n=0.7$ & $B_{g}=\left(-0.168 v^{3}+1.9966 v^{2}-7.2524 v+37.005\right) \times 100 \%$ & 1.00 \\
$n=0.9$ & $B_{g}=\left(-0.7305 v^{3}+7.7485 v^{2}-22.062 v+42.259\right) \times 100 \%$ & 1.00 \\
$n=1.1$ & $B_{g}=\left(0.2767 v^{3}-2.97 v^{2}+839583 v+21.11\right) \times 100 \%$ & 1.00 \\
$n=1.3$ & $B_{g}=\left(0.2108 v^{3}-2.866 v^{2}+7.2536 v+19.772\right) \times 100 \%$ & 1.00 \\
\hline
\end{tabular}

TABLE 5: The content change of particles with different sizes and the corresponding particle breakage under different loading modes.

\begin{tabular}{cccccccccc}
\hline \multirow{2}{*}{ Samples } & & & \multicolumn{3}{c}{ Particle size $(\mathrm{mm})$} & & \\
& & $0-2$ & $2-5$ & $5-10$ & $10-15$ & $15-20$ & $20-25$ & $25-30$ & $B_{g}(\%)$ \\
\hline \multirow{4}{*}{ Direct loading } & $1: 1: 1: 1$ & 2.87 & 4.41 & 12.75 & -2.71 & -1.29 & -9.11 & -6.92 \\
& $n=0.7$ & 3.90 & 6.58 & 18.67 & -24.63 & -1.70 & -2.49 & -0.33 & 20.02 \\
& $n=0.9$ & 3.64 & 5.67 & 13.98 & -12.57 & -1.16 & -5.37 & -4.17 & 29.14 \\
& $n=1.1$ & 4.52 & 7.08 & 17.76 & -17.35 & -4.56 & -2.81 & -4.64 & 29.36 \\
& $n=1.3$ & 4.55 & 6.00 & 14.75 & -9.09 & -5.24 & -4.13 & -6.85 & 25.30 \\
\hline \multirow{3}{*}{ Step loading } & $1: 1: 1: 1$ & 9.03 & 10.27 & 17.69 & -5.10 & -12.08 & -6.80 & -13.04 & 36.99 \\
& $n=0.7$ & 12.14 & 12.59 & 22.28 & -25.51 & -8.69 & -5.63 & -7.15 & 47.01 \\
& $n=0.9$ & 9.88 & 11.11 & 20.71 & -24.71 & -4.44 & -7.09 & -5.45 & 41.69 \\
& $n=1.1$ & 12.73 & 13.91 & 22.28 & -24.37 & -5.89 & -7.71 & -10.95 & 48.92 \\
& $n=1.3$ & 10.57 & 11.84 & 22.04 & -17.61 & -6.91 & -10.29 & -9.63 & 44.44 \\
\hline
\end{tabular}

loading, the sample was first compacted $10 \mathrm{~mm}$, and the sample height was calculated as H10. The sample was then unloaded, reloaded to $\mathrm{H} 10$, compacted $10 \mathrm{~mm}$ further, and the sample height was calculated as H20. The sample was then unloaded, reloaded to $\mathrm{H} 20$, and compacted $10 \mathrm{~mm}$ further, and the sample height was calculated as H30. Finally, the sample was unloaded, reloaded to H30, then compacted $10 \mathrm{~mm}$ further, and the sample height was calculated as H40 before it was unloaded.

Figure 9 shows the comparison of particle breakage of the loading mode. It can be seen from Table 5 and Figure 9 that the particle breakage was stronger in stepwise loading, and the particle breakage of samples of various gradations increased. Specifically, the particle breakage increased by $16.97 \%$ for the $1: 1: 1: 1$ sample, which was $84.77 \%$ higher than in the case of direct loading, $17.87 \%$ for the $n=0.7$ sample, which was $61.32 \%$ higher than in the case of direct loading, $18.40 \%$ for the $n=0.9$ sample, which was $79.00 \%$ higher than in the case of direct loading, $19.56 \%$ for the $n=1.1$ sample, which was $66.62 \%$ higher than in the case of direct loading, and $19.14 \%$ for the $n=1.3$ sample, which was $75.65 \%$ higher than in the case of direct loading. Besides, it also could be seen that continuous grading samples had a lower increase in particle breakage than the discontinuous grading sample.

Although the loading method and gradation both have impacts on the particle breakage of the samples, it could be found from Figure 9 that the two influencing factors do not interfere with each other. Therefore, in the construction and compaction of bedding course, engineering specialists and 


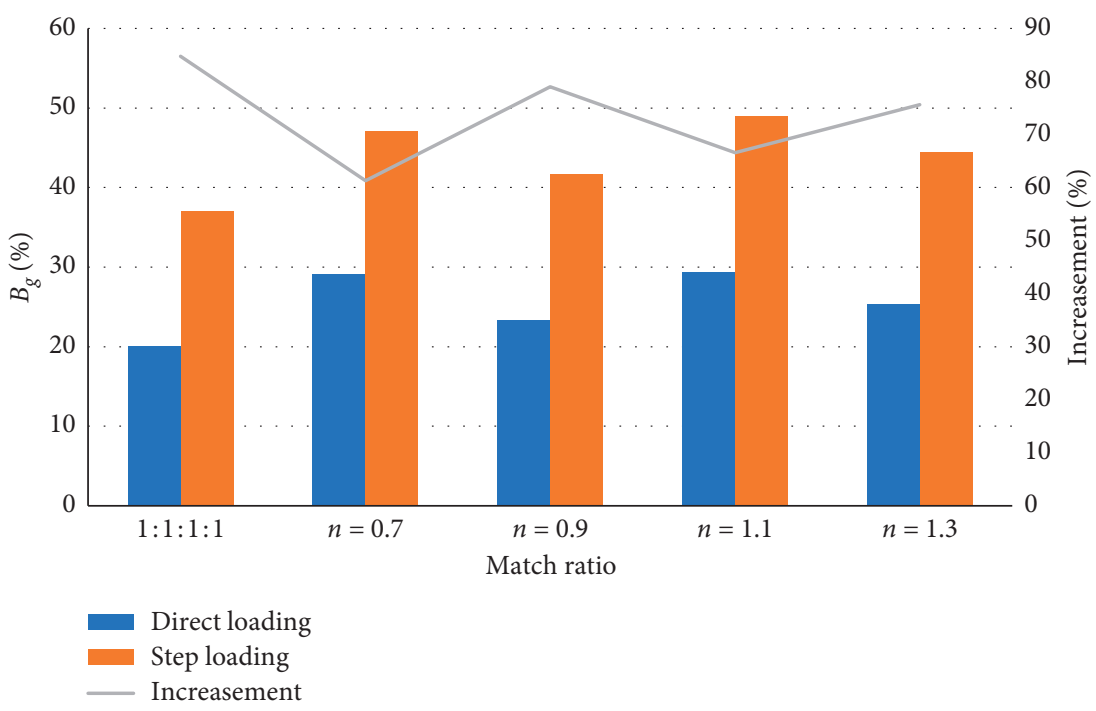

Figure 9: The comparison of particle breakage of loading mode.

technicians tend to emphasize the level of compaction more than the loading mode.

\section{Conclusions}

The subsidence of urban pavement is becoming frequent accidents, and backfill is the primary means of remedy. Crushed stone is a commonly used aggregate for backfill material in engineering, and its compaction behavior under load needs to be well understood. In this work, a series of compaction tests were carried out on the same batch of crushed stone samples with the same gradation. The content changes of particles with different sizes were analyzed, the particle breakage characteristics during the compaction process were discussed, and the difference in particle breakage caused by loading speed and loading mode was examined. This study thus provides an experimental basis and reference for the selection and use of backfill aggregate in urban subsidence areas. The main conclusions are as follows:

(1) For all samples, the content of particles that were crushed during compaction was always less than $40 \%$. The particles with the strongest breakage varied with sample gradation. The mass change after compaction was the greatest for the sample when $n=0.7$ and the smallest for the sample when $n=1.3$. Thus, structural stability due to particle breakage from compaction was the least affected for the sample when $n=1.3$, for which skeletal deformation was the least.

(2) The particle breakage could be divided into four categories: complete fragmentation, complete rupture, local fragmentation, and surface grinding. They affected the particle size distribution after compaction to varying degrees.

(3) The particle breakage could be expressed as a cubical parabola of loading speed, whose coefficients are related to the sample gradation. For the $1: 1: 1: 1$ and $n=0.7$ samples, the particle breakage firstly decreased and then increased with escalating loading speed. For the samples when $n=1.1$ and $n=1.3$, the particle breakage firstly increased and then decreased with escalating loading speed. For the sample when $n=0.9$, as the loading speed increased, the particle breakage had an initial decrease, followed by an increase and eventually another decrease.

(4) Stepwise loading rendered stronger particle breakage than direct loading, and the increase of particle breakage due to the loading mode was more evident for continuous grading samples than discontinuous grading samples.

\section{Data Availability}

The data used to support the findings of this study are available from the corresponding author upon request.

\section{Conflicts of Interest}

The author declares that they have no conflicts of interest.

\section{Acknowledgments}

This work was supported by the National Natural Science Fund (51808481) and the Natural Science Foundation of Jiangsu Province of China (BK20170477).

\section{References}

[1] C. Zhang, D. Zhang, M. Wang, and S. Liu, "Catastrophe mechanism and control technology of ground collapse induced by urban tunneling," in Proceedings of the 2nd National Conference on Engineering Safety and Protection, pp. 51-57, Beijing, China, August 2010.

[2] C. Zhang, D. Zhang, M. Wang, Q. Li, and S. Liu, "Catastrophe mechanism and control technology of ground collapse induced by urban tunneling," Rock and Soil Mechanics, vol. 31, no. S1, pp. 303-309, 2010. 
[3] S. Wang, Analysis and Study on Subsidence Mechanisms of Road Caused by Leakage of Urban Underground Pipeline, Zhengzhou University, Zhengzhou, China, 2017.

[4] C. Zhang, D. Zhang, and M. Wang, "Analysis of ground subsidence induced by shallow-buried tunnel construction and its control techniques," Chinese Journal of Rock Mechanics and Engineering, vol. 26, no. S2, pp. 3601-3608, 2007.

[5] D. Lian, "On the ground and the reasons for the collapse of the environmental impact," Journal of Hunan University (Natural Sciences), vol. 35, no. 11, pp. 88-91, 2008.

[6] P. Yuan, Study on Collapse Mechanism of Soil Subgrade of City Roads by Water Erosion, China University of Mining and Technology, Xuzhou, China, 2014.

[7] Y. Wang, R. Xie, L. Ren, and J. Zhang, "Analysis of disastercausing mechanism and control of seepage in ground collapses of cities," Journal of Hefei University (Natural Sciences), vol. 25, no. 1, pp. 59-62, 2015.

[8] X. Xu, W. Zhou, Z. Han, S. Qin, and J. Li, "Research on compaction properties of soil-aggregate mixture," Rock and Soil Mechanics, vol. 31, no. S2, pp. 115-148, 2010.

[9] J. Zha, Study on the Foundational Problems of Mining Subsidence Controlled in Waste Stow, China University of Mining and Technology, Xuzhou, China, 2008.

[10] Z. Liu, Compaction Properties of Gangue and Its Application in Backfilling Coal Mining, China University of Mining and Technology, Xuzhou, China, 2014.

[11] M. R. Coop, "The mechanics of uncemented carbonate sands," Géotechnique, vol. 40, no. 4, pp. 607-626, 1990.

[12] ASTM International, ASTM C39/C39M-15a, Standard Test Method for Compressive Strength of Cylindrical Concrete Specimens, 10.1520/C0039_C0039M-15A, West Conshohocken, PA, USA, 2015.

[13] A. N. Talbot and F. E. Richart, "The strength of concrete and its relation to the cement, aggregate and water," Bulletin, University of Illinois Engineering Experiment Station, vol. 11, no. 7, pp. 1-118, 1923.

[14] H. Kong, L. Wang, and H. Zhang, "Fractal and re-breakage behavior of the saturated rock granular material under compaction," Arabian Journal of Geosciences, vol. 14, 2020.

[15] H. Kong, L. Wang, and H. Zhang, "The variation of grain size distribution in rock granular material in seepage process considering the mechanical-hydrological-chemical coupling effect: an experimental research," Royal Society Open Science, vol. 7, no. 1, Article ID 190590, 2020.

[16] Y. Gao, B. Zhang, W. Liu, and Y. Ai, "Experimental study on particle breakage behavior of rockfills in large-scale triaxial tests," Rock and Soil Mechanics, vol. 30, no. 5, pp. 1237-1246, 2009.

[17] X. Lei, Z. Yang, X. Zhang, Y. Tu, S. Liu, and Y. Hu, "Shear properties and rock block breakage characteristics of soil-rock mixtures," Rock and Soil Mechanics, vol. 39, no. 3, pp. 899916, 2018.

[18] H. Liu, H. Qin, Y. Gao, and Y. Zhou, "Experimental study on particle breakage of rockfill and coarse aggregates," Rock and Soil Mechanics, vol. 26, no. 4, pp. 562-566, 2005.

[19] S. Wei, J. Zhu, Q. Qian, and F. Li, "Particle breakage of coarsegrained materials in triaxial tests," Chinese Journal of Geotechnical Engineering, vol. 31, no. 4, pp. 533-538, 2009.

[20] I. Einav, "Breakage mechanics-part I: theory," Journal of the Mechanics and Physics of Solids, vol. 55, no. 6, pp. 1274-1297, 2007.

[21] B. O. Hardin, "Crushing of soil particles," Journal of Geotechnical Engineering, vol. 111, no. 10, pp. 1177-1192, 1985.
[22] P. V. Lade, J. A. Yamamuro, and P. A. Bopp, "Significance of particle crushing in granular materials," Journal of Geotechnical Engineering, vol. 122, no. 4, pp. 309-316, 1996.

[23] R. J. Marsal, "Large scale testing of rockfill materials," Journal of the Soil Mechanics and Foundations Division, vol. 93, no. 2, pp. 27-43, 1967. 